\title{
On Classifications of Fallacies
}

\section{MICHAEL F. SCHMIDT}

\author{
San Jose State University
}

Research suggests to me the conclusion that three fundamental kinds of fallacies are-interrogative, premisory, and inferential. However, in this article, the focus will be on premisory fallacies. In particular, the article aims to show that there are four distinct kinds of premisory fallacies, "begging the question", "inconsistency", "falsity", and "omission". The article begins with a very brief review of some schools of thought about classifying fallacies; then it turns to the task of reviewing some actual classifications of fallacies to see what the tendencies are; five tendencies are found; from them emerges the conclusion that "incomplete information" is distinct from "false premise" and from "invalid inference", that "begging the question" is distinct from all three, and that "inconsistent premises", "false premise", "incomplete information", and "begging the question" form a natural constellation of premisory fallacies, distinct from the fallacy of many questions and from the fallacies of invalid inference. Appended is a bibliography of recent and contemporary writings on the topic of fallacies.

\section{Schools of thought}

There flourish several schools of thought about the classification of fallacies. Let us review their main tenets.

It is well known that Augustus De Morgan claimed: "There is no such thing as a classification of the ways in which men may arrive at an error: it is much to be doubted whether there ever can be [1] $^{\prime}$

C.L. Hamblin writes: "We [in 1970] have no theory of fallacy at all, in the sense in which we have theories of correct reasoning or inference. Yet we feel the need to ticket and tabulate [fallacies]....'[2] Gerald J. Massey argues that an account of fallacies presupposes a theory of invalidity and that "a theory of invalidity has yet to be developed" [3], while others argue for a "theory of reasoning". One of this journal's referees points out that "no a priori scheme of classifications can fairly be evaluated until there is some unified theory of argument."

And, Peter Ramus (in 1543) wrote:

First, should not the overall description of [dialectical] vices itself arise from the direct opposition of virtues so that, for every kind of virtue there should be just one kind of vice? And in so far as there are two overall virtues in dialectic, one of Invention and one of Judgment, so there ought to be two overall vices, one opposed and hostile to true Invention, the other to correct Judgment; ....[4]

Now, let us review some important and interesting classifications of fallacies-those of Aristotle, Richard Whately, John Stuart Mill, H.W.B. Joseph, W. Ward Fearnside, Howard Kahane, and Ronald Munson-and then see what the tendencies are.

\section{Aristotle}

Probably the best known classification is Aristotle's. His On Sophistical Refutations begins: 
Let us now discuss sophistic refutations, i.e. what appear to be refutations but are really fallacies instead....

That some reasonings are genuine, while others seem to be so but are not, is evident. This happens with arguments as also elsewhere, through a certain likeness between the genuine and the sham. [5]

According to Aristotle, sometimes reasoning and refutation fail because arguments depend upon language:

\section{It is impossible in a discussion to bring in the actual things discussed: we use their names as symbols instead of them; and therefore we suppose that what follows in the names, follows in the things as well, ...[6]}

Fallacies due to language include: word ambiguity, grammatical ambiguity (i.e., amphiboly), accent, and three others.

At other times reasoning and refutation fail because of factors that are "independent of language".[7] Fallacies of this sort include: ignoratio elenchi, begging the question, false cause, many questions, and three others.

Notice that Aristotle discusses these two sorts of fallacies in connection with what he calls "contentious arguments" as opposed to "demonstrative arguments" and "dialectical arguments"; that is, in On Sophistical Refutations he focuses more on questions about refuting an opponent than on questions about proposing a scientific explanation or a solution to a problem; and, consequently, he focuses more on sham refutations than on sham explanations or sham solutions to problems.

Notice too that Aristotle acknow ledges the possibility of classifying fallacies differently; for example.

The right way, then, is either to divide apparent proofs and refutations as above, or else to refer them all to ignorance of what 'refutation' is [ignoratio elenchi], and make that our startingpoint: for it is possible to analyse all the aforesaid modes of fallacy into breaches of the definition of a refutation. [8]
Moreover, in his Rhetoric Aristotle lists some spurious 'lines of argument"; there are nine in all; "the first...arises from the particular words employed"'[9]; this first spurious line of argument has two varieties: (a) "when, without having gone through any reasoning process, we make a final statement as if it were the conclusion of such a process" [10]; and, (b) when we use "similar words for different things" [11] (probably a reference to a number of sorts of ambiguity). Note that the former variety is not among the fallacies enumerated in On Sophistical Refutations.

The remaining eight spurious "lines of argument" are presumably independent of language; they include some that are enumerated in On Sophistical Refutations, including the special case of "false cause" now known as "post hoc, ergo propter hoc"; and, they also include some that are not enumerated in On Sophistical Refutations, including "the use of indignant language, whether to support your own case or to overthrow your opponent's" .[12]

\section{Whately}

In Richard Whately's Elements of Logic we find a somewhat different classification: Fallacies are of two main sorts: logical and material. First, logical fallacies occur "when the fault is, strictly, in the very process of Reasoning" [13], i.e., "[w] here the Conclusion does not follow from the Premises. "[14] Second, in the case of material fallacies, although the conclusion does follow from the premises, something else goes wrong. In particular, there are those material fallacies that are due to an "unduly assumed" premise and those due to ignoratio elenchi.[15]

Under the heading of "premise unduly assumed", Whately includes petitio principii (i.e., begging the question) and "false or unsupported premise"; and, under the heading of ignoratio elenchi, he includes ad hominem, ad verecundiam, etc., "shifting 
ground", and two others. [16]

Notice that Whately acknowledges that the classification of fallacies is, to a degree, arbitrary and uncertain:[17]

..., from the elliptical form in which all reasoning is usually expressed, and the peculiarly involved and oblique form in which Fallacy is for the most part conveyed, it must of course be often a matter of doubt, or rather, of arbitrary choice, not only to which genus each kind of fallacy should be referred, but even to which kind to refer any one individual Fallacy. [18]

He does not explain why it is indeterminate "to which genus each kind of fallacy should be referred", but does explain why it is indeterminate[19] "to which kind to refer any one individual fallacy". He says:

For, since, in any Argument, one Premiss is usually suppressed, it frequently happens, in the case of a Falla$c y$, that the hearers are left to the alternative of supplying either a Premiss which is not true, or else, one which does not prove the Conclusion. [20]

He gives the following example: if a person argues from the premise that 'the country is distressed' to the conclusion that 'the government is tyrannical', "we must suppose him to assume either that every distressed country is under a tyranny,' which is a manifest falsehood, or, merely that 'every country under a tyranny is distressed,' which, however true, proves nothing". [21]

\section{Mill}

In John Stuart Mill's A System of Logic we find a similar classification: Fallacies are of two main sorts: "Fallacies of Simple Inspection" and "Fallacies of Inference" .[22]

Fallacies of Simple Inspection (or, a priori fallacies; or, natural prejudices) simulate genuinely self-evident propositions (if there are any genuinely selfevident propositions). Note that Mill does say:
As it is foreign to the purpose of the present treatise to decide between these conflicting [methaphysical] theories, we are precluded from inquiring into the existence, or defining the extent and limits, of knowledge a priori, and from characterising the kind of correct assumption which the fallacy of incorrect assumption, now under consideration, simulates.[23]

Fallacies of Inference comprise (1) the Inductive Fallacies of Observation, (2) the Inductive Fallacies of Generalisation, (3) the Deductive Fallacies of Ratiocination, and (4) Fallacies of Confusion.[24] Fallacies of Confusion are "fallacies in which the source of error is not so much a false estimate of the probative force of known evidence, as an indistinct, indefinite, and fluctuating conception of what the evidence is. "[25]

Under the heading of Inductive Fallacies of Observation, Mill includes "non-observation" and "mal-observation". [26] Under the heading of Inductive Fallacies of Generalization, one might include the two forms of the Fallacy of Hasty Ceneralization: (a) generalization from an overly small sample and (b) generalization from an unrepresentative sample. Under the heading of Deductive Fallacies of Ratiocination, one might include the Fallacy of Affirming the Consequent, the Fallacy of Denying the Antecendent, etc. And, under the heading of Fallacies of Confusion, one might include equivocation, the "black or white" fallacy, the argument from the heap, and the slippery slope fallacy.

Additionally, Mill quotes Whately with approval-concerning the reason why it is determinate to which class of fallacies to refer any actual error. [27]

\section{Joseph}

In H.W.B. Joseph's An Introduction to Logic there is a return to Aristotle, a return both to the letter of Aristotle's On Sophistical Refutations and to its spirit. Joseph quotes the Greek, provides translations, and follows Aris- 
totle's classification of fallacies[28]

Joseph does raise one objection against Aristotle's classification: "It suffers", he says, "from the defect of not positively characterizing one group" [29]; that is, as a group, fallacies that are not due to language (extra dictionem) have no positive characterization, and are merely contrasted with those that are due to language (in dictione).

Joseph also raises objections to Whately's classification: he objects primarily to Whately's inclusion of "arguments which have no fault except that their premisses are false" $[30]$; that is, under the heading of "premise unduly assumed", Whately includes not only petitio principii but also "false or unsupported premise", and Joseph objects thus:

...it is true that in [doing so] he follows the words of Aristotle [Topics, 100b, 23; see also Topics, 162b, 3 and 12-15]; but in the body of his treatise Aristotle proceeds as if he had not included them. And the practice of Aristotle appears preferable in this respect; ... [31]

...it is good advice to a disputant to consider well the truth of the premisses he is asked to grant, or to a solitary thinker to consider well the truth of what he supposes to assume and build upon. Nevertheless there seems to be a real difference between a plausible but inconclusive argument, which we can see through by clearer and more attentive thinking, and a false proposition (whether or not plausible), which cannot be exploded by any more attentive consideration of itself, though it may [be exploded] by reasonings that are within our power. For this reason the extension of the term fallacy to cover 'any false assumption employed as a premiss' seems undesirable; ...[32]

\section{Fearnside}

In W. Ward Fearnside's About Thinking (and also in the older Fallacy, The Counterfeit of Argument, coauthored by Fearnside and William B. Holther), we find yet another classifi- cation: Fallacies are of three main sorts: material, psychological, and logical. Fearnside explains the classification by means of a figurative analogy between the process of reasoning and a manufacturing process-in which "three kinds of things can go wrong" [33]: the raw materials may be defective; the workers may make mistakes; or the machinery they use may be defective.

As Johnson and Blair point out, Fearnside introduces sub-groupings "that are clearly pedagogical in inspiration" [34]; for example, "stirring up prejudice", "rationalization and lip service", and "diversions". [35]

In what follows, I will use traditional names even in cases where Fearnside translates and/or modernizes them. Under the heading of Material Fallacies, Fearnside includes the two forms of the Fallacy of Hasty Generalization, post hoc, ergo propter hoc, the (Material) Fallacies of Composition and Division, the "black or white" fallacy, the argument from the heap, the slippery slope fallacy, begging the question, and seven others. Under the heading of Psychological Fallacies, Fearnside includes ad hominem, ad verecundiam, ad populum, ad misericordiam, ad ignorantiam, ad baculum, and ten others. Under the heading of Logical Fallacies, Fearnside includes the Fallacy of Affirming the Consequent, the Fallacy of Denying the Antecedent, and eight other formal fallacies.

\section{Kahane}

In "The Nature and Classification of Fallacies", Howard Kahane explains the classification of fallacies employed in his textbook Logic and Contemporary Rhetoric. And, he also presents and explains a second classification, based on "the psychological mechanisms that lead us to reason poorly". [36] We will survey only the former classification.

Fallacies are of three main sorts: invalid inference, unwarranted premise, and suppressed evidence. As before, I will use traditional names 
even in cases where Kahane translates or modernizes them. Under the heading of "invalid inference", Kahane includes ad verecundiam, ambiguity, the "slippery slope" fallacy, ad hominem, the two forms of the Fallacy of Hasty Generalization, and seven others. Under the heading of "unwarranted premise", Kahane includes the straw man fallacy, begging the question, inconsistency, and three others. Under the heading of "suppressed evidence", Kahane includes the fallacy of suppressed evidence.

Kahane denies that a fallacious argument is simply an invalid argument that appears to be valid; he also denies that a fallacious argument is simply an unsound argument that appears to be sound, since question-begging arguments that happen to have a true conclusion are sound but fallacious:[37]

\begin{abstract}
Nor can we say that a fallacious argument is one that is either unsound or question begging. For this criterion focuses too much on arguments and too little on arguers.... It is, in other words, not sufficiently pragmatic or epistemic. It is not the actual truth or falsity of premises that counts, but rather the rationality of belleving or accepting those premises.[38]
\end{abstract}

For a cogent argument, Kahane's first requirement is "valid inference" and his second requirement is "warranted premises". To these he adds a third:
...which is, roughly, the use of all available or known evidence. This is the requirement appealed to, for instance, when we reject a use of Mill's Methods because relevant information has been ignored, or when we accuse someone of the fallacy of biased statis- tics,... [39]

Hence, the three sorts of fallacies.

Notice that Kahane raises an objection to Whately's classification: he objects that Whately's category, ignoratio elenchi, does not belong "in his general category of non-logical fallacies...because arguments which validly yield an irrelevant conclusion generally fail to validly yield the conclusion at issue" $[40]$; ignoratio elenchi should, therefore, be subsumed under the heading of "invalid inference".

Notice too that like virtually all of his predecessors Kahane remarks about overlapping categories: that his three categories, invalid inference, unwarranted premise, and suppressed evidence, "are not mutually exclusive ...[since, for example, an]... argument which is invalid may contain an unwarranted premise and/or suppress evidence ${ }^{\prime \prime}$.[41]

\section{Munson}

In Ronald Munson's The Way of Words we find a very different classification. Munson classifies traditional fallacies not according to their source but rather according to their typical role. That is, instead of classifying fallacies as arising from, say, language, or prejudice, or observation, or reasoning, he classifies them as (1) "committed in making a case for a claim, in arguing for a position", (2) committed in "criticizing or attempting to refute a claim", and (3) committed in "defending a claim against counterarguments", [42] Munson calls them: (1) Fallacies, (2) Sophistical Refutations, and (3) Sophistical Defenses, respectively.

Under the heading of Fallacies, Munson includes ad ignorantiam, ad verecundiam, ad misericordiam, ad baculum, ad populum, false cause, begging the question, and four others. Under the heading of Sophistical Refutations, he includes ad hominem, tu quoque, the straw man fallacy, and three others. And, under the heading of Sophistical Defenses, he includes shifting ground, hedging, shifting the burden of proof, and three others.

Notice that Munson adopts Aristotle's contrast between propounding and refuting, and adds defending.

Additionally, in the introduction to the chapter in which these 23 fallacies \& sophistries are presented, Munson makes two special points. First:

There's no particular magic in any of the common schemes of classification, and they all have good points. 
Lumping has the disadvantage of failing to call attention to certain distinctive features of fallacies. On the other hand, splitting has the disadvantage of creating so many distinct categories that they can't all be kept in mind.

Since the primary purpose of talking about fallacies in this book is to warn people about recurrent kinds of bad arguments and to help them detect such arguments in ordinary affairs, it's perhaps better to lump than to split. [43]

Second: Munson is careful to point out that some fallacies and sophistries fall under more than one category.

For Munson, although the failure to meet the condition that the premises must be true is, strictly speaking, not a fallacy, it is one of four grounds on which to "challenge an argument"; likewise, although the failure to meet the condition that the premises must "tell the whole truth" is, strictly speaking, not a fallacy, it is one of the four grounds on which to "challenge an argument".

(1) Challenging the Truth of the Premises. [44]

(2) Challenging the Relevance of the Premises. [45]

(3) Challenging the [Sufficiency] of the Premises. [46]

(4) Challenging the Fairness of the Premises. ... We are aware that all facts and all reasons-pro and con, favorable and unfavorable, for and against-can't be given in the premises of an argument, and we don't demand the impossible. All we want is a just representation of the relevant and important considerations. ... Any bureaucrat worth his pension can show that the program he administers is "by and large successful" if he judiciously selects the right sort of cases and closes his eyes to the wrong sort. [47]

\section{Tendencies}

Let us now see what the tendencies are: First, that the basic categories or classes of fallacies are increasing in number: Aristotle distinguished fallacies "due to language" from those that are not due to language; Whately distinguished "logical" and "material" fallacies; Mill distinguished those due to "inference" and those due to "observation"; but Fearnside, Kahane, and Munson each distinguish three basic kinds of fallacies. Also, recall Joseph's criticism of Aristotle's classification: that it "suffers from the defect of not positively characterizing one group", that is, as a group, fallacies that are not due to (say,) language have no positive characterization, and are merely contrasted with those that are due to language. And, compare Kahane's observation that a fallacious argument is not an invalid argument that appears to be valid, and that a fallacious argument is not an unsound argument that appears to be sound, since question-begging arguments that happen to have a true conclusion are sound but fallacious. It appears to be Kahane's point that the fallacy of begging the question should not be classed under either - not under "invalid inference", nor under "false premise". Perhaps it can be concluded that without a sufficiently large number of basic categories, there is a likelihood that the "last" category will be a catch-all.

Second, there is the question whether the category, "false premise" [or anything like it], belongs under the category, "Fallacy". The tendency is to include it; Aristotle includes "false premise"; Whately includes "premise unduly assumed"; Mill includes "malobservation"; Kahane includes "unwarranted premise", and Munson makes "false premise" one of the four grounds on which to "challenge an argument"; only Joseph excludes it.

Third, there is the question whether the category, "incomplete information", belongs under the category, "Fallacy". The tendency is to include it; Mill includes "non-observation", Kahane includes "suppressed evidence", and Munson makes "unfair-

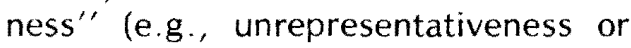
omission) one of the four grounds on which to "challenge an argument".

Fourth, there is the question whether 
Fearnside's introduction of the category, "psychological" fallacy, should be retained. Though the analogy on which it is based is an attractive one, between the process of reasoning and a manufacturing process, it stands alone in mixing categories in a radical way. Aristotle's considerations were rhetorical; recall that he was concerned with "refutations". Whately distinguished between "logical" and "material" fallacies; Mill, between those due to "inference" and those due to "observation"; Joseph and Kahane follow suit; and Munson distinguishes on rhetorical grounds, between fallacies committed in making a case for a claim, committed in criticizing or attempting to refute a claim, and committed in defending a claim against counterarguments. Also recall $\mathrm{Ka}$ hane's two classifications; and, he maintains that fallacies can be classified in either of two ways, in terms of "what makes an argument fallacious" or in terms of "what leads us to commit fallacies" [48]; and though he attempts a "psychological classification", he acknowledges that psychological mechanisms are "in the realm of psychology, not philosophy or logic' [49]; and let me add, they are, of course, in the realm of cognitive science.

Fifth, there is the question whether it is indeterminate, as Whately says, "to which genus each kind of fallacy should be referred". As Whately points out, an actual argument can be analyzed in a plurality of ways, each way resulting in the attribution of a different fallacy; and, as Kahane points out, an argument may actually contain more than one fallacy; but none of this reasoning comes even close to supporting Whately's claim that the classification of fallacies is, to a degree, arbitrary and uncertain. It is, of course, plain from the preceding paragraph that there is a plurality of classificatory grounds, e.g. psychological, according to rhetorical function, or in terms of features of arguments; but this does not make it indeterminate to which genus of a particular classification each kind of fallacy belongs. Of course, in the case of a functional classification, a fallacy of a particular logical kind may perform different functions on different occasions; and, in the case of a psychological classification, a fallacy of a particular logical kind may be the result of different psychological mechanisms on different occasions.

\section{Conclusion}

From these schools and trends, reasoning leads to the conclusion that "begging the question" is distinct from "false premise" and from "invalid inference". Recall Kahane's insight that a question-begging argument can have true premises and, therefore, be sound. For Whately "begging the question" falls under the heading of "premise unduly assumed"; similarly, for Kahane "begging the question" falls under the heading of "unwarranted premise". The fallacy of "begging the question" involves reasoning from premises that are flawed because one or more of them are what is to be proved.

It also follows that "incomplete information" is distinct from all three. Mill contrasts "non-observation" with "mal-observation" ["incomplete information" with "false premise"]; Kahane contrasts "suppressed evidence" with "unwarranted premise"; Munson contrasts "unfairness" (e.g., unrepresentativeness or omission) with "falsity". Alfred Sidgwick, too, contrasts "incomplete information" with "false premise"; his third "general objection to any argument" is that "some important factor has been overlooked or forgotten"'[50], whereas his fourth is that "some absurdity (or at least untruth) must ... be believed" [51] in order for the argument to do its job. The fallacy of "incomplete information" involves reasoning from a set of premises that fails to "tell the whole truth" (or, that fails to tell enough to be representative).

Of course, the fallacy of "false premise" involves reasoning from one or more untrue premises. 
In addition to "false premise", "incomplete information", and "begging the question" , there is a fourth kind of fallacy associated with the premises of an argument: "inconsistent premises". Although an inconsistent set of premises contains at least one false premise and, therefore "inconsistent premises" might be thought to fall under the heading of "false premise", inconsistency is a more fundamental kind of flaw than falsity since inconsistency is a purely logical flaw and since truth presupposes consistency; therefore, "inconsistent premises" cannot be subsumed under "false premise" and must be differentiated from it. The fallacy of "inconsistent premises" involves reasoning from a set of premises that is flawed by being selfcontradictory.

Thus, "inconsistent premises", "false premise", "incomplete information", and "begging the question" form a natural constellation of premisory fallacies.

In contrast to this constellation of premisory fallacies, there is the interrogative fallacy of "many questions" and a variety of inferential fallacies, a variety of non sequiturs, ranging from strictly deductive fallacies, through the inductive fallacy of "generalizing from an unrepresentative sample"[52], to "material non sequiturs" such as non causa pro causa reasoning, the gambler's fallacy, and the several fallacies of arguing ad this and ad that (for example, arguing ad populum, i.e., arguing as though enthusiasm arising from popular opinion were constitutive of truth).[53] Thus:

\section{Fallacies}

Interrogative

Many questions

\section{Inferential}

Premisory

Begging the question

Inconsistency

Falsity

Omission strictly deductive fallacies

generalizing from an unrepresentative sample

material non sequiturs

\section{Notes}

[1] Augustus De Morgan, Formal Logic, 1847 (London: The Open Court Company, 1926, edited by A.E. Taylor), p. 237; page reference is to the original page number, which is in square brackets in boldface type in the 1926 reprint edition.

[2] Charles L. Hamblin, Fallacies (London: Methuen \& Co. Ltd., 1970), p. 11

[3] Gerald J. Massey, "The Fallacy behind Fallacies", in Midwest Studies in Philosophy, Volume 6,
The Foundations of Analytic Philosophy, edited by Peter A. French, Theodore E. Uehling Jr., and Howard $K$. Wettstein (Minneapolis: University of Minnesota Press, 1981), p. 494.

[4] Peter Ramus, Aristotelicae Animadversiones ["Remarks on Aristotle's], quoted from Hamblin's Fallacies, p. 138.

[5] Aristotle, On Sophistical Refutations, in The Works of Aristotle, translated into English, under the editorship of W.D. Ross, Vol. 1 (London: Oxford University Press, 1928; reprinted, 1963), 164a, 20-26. 
[6] Ibid., 165a, 5-9.

[7] Ibid, 166b, 22.

[8] Ibid., 168a, 17-20.

[9] Aristotle, Rhetoric, in The Basic Works of Aristotle, edited by Richard McKeon (New York: Random House, Inc., 1941), 1401a, 1.

[10] Ibid., 1401a, 2-3.

[11] Ibid., 1401a, 13-14; see Aristotle's examples, 1401a, 14-23.

[12] Ibid., 1401b, 4.

[13] Richard Whately, Elements of Logic, 1826; 9th ed., 1848 (London: Longmans, Green, Reader, and Dyer, 1866), p. 108.

[14] Ibid., p. 105.

[15] Ibid., p. 108.

[16] Ibid., p. 108.

[17] Ibid., pp. $104 \& 112$.

[18] Ibid., pp. 104-105.

[19] Ibid., p. 105.

[20] Ibid., p. 105.

[21] Ibid., p. 105.

[22] John Stuart Mill, A System of Logic, 1843; 8th ed., 1872 (London: Longmans, Green and Co., 1936), p. 487.

[23] Ibid., p. 489.

[24] Ibid., p. 487.

[25] Ibid., p. 530.

[26] Ibid., p. 506.

[27] Ibid., p. 487; Mill quotes from Whately virtually the same passages quoted above, from pp. 104-105.

[28] H.W.B. Joseph, An Introduction to Logic, 1906; 2nd ed., 1916 (Oxford: Clarendon Press, 1961); see pp. 577-578.

[29] Ibid., pp. 574-575.

[30] Ibid., p. 575.

[31] Ibid., pp. 575-576.
[32] lbid., p. 576.

[33) W. Ward Fearnside, About Thinking (Englewood Cliffs, New Jersey: Prentice-Hall, Inc., 1980), p. 5.

[34] Ralph H. Johnson and J. Anthony Blair, "The Recent Development of Informal Logic", in Informal Logic, The First International Symposium, edited by J. Anthony Blair and Ralph $H$. Johnson (Inverness, California: Edgepress, 1980), p. 15.

[35] Johnson and Blair also point out that lists of fallacies have changed in a number of ways; and, though they do not mention him in this connection, Fearnside's list of fallacies displays two of these changes: (1) "Latin labels have been translated in[to] English, or replaced with more descriptive English labels" (Johnson \& Blair, p. 16) and (2) "completely new fallacies have been added as writers have canvassed real arguments about current issues..., and have pondered the responsibilities of arguer and audience as reflective citizens or consumers" (Johnson \& Blair, p. 16). In particular, Fearnside makes traditional fallacies breathe with life, and he adds new ones such as "stereotyping" and "half-truth"; in Fallacy, The Counterfeit of Argument, pages 26-27 cover "stereotyping" under the heading of "faulty analogy" and page 100 presents the notion of a halftruth in connection with personal attacks, i.e. in connection with ad hominem arguments.

[36] Howard Kahane, "The Nature and Classification of Fallacies", in Informal Logic, The First International Symposium, edited by $\mathrm{J}$. Anthony Blair and Ralph $\mathrm{H}$. Johnson (Inverness, California: Edgepress, 1980), p. 33.

[37] Ibid., p. 31.

[38] Ibid., p. 32. 
[39] lbid., p. 32.

[40] Ibid., p. 33.

[41] Ibid., p. 33.

[42] Ronald Munson, The Way of Words (Boston: Houghton Mifflin Company, 1976), p. 262.

[43] Ibid., p. 261.

[44] Ibid., pp. 185-187.

[45] lbid., pp. 187-189.

[46] lbid., pp. 189-194.

[47] Ibid., pp. 194-197.

[48] Kahane, "The Nature and Classification of Fallacies", p. 33.

[49] Ibid., p. 33

[50] Alfred Sidgwick, Fallacies, a view of logic from the practical side, 1883; 2nd ed., 1886; 3rd ed., 1901 (New York: D. Appleton \& Co., 1895), p. 178.

[51] Ibid., p. 178.

[52] Thomas Leddy, "Is There a Fallacy of Small Sample?" Informal Logic, Vol. VIII, No. 1, pp. 53-56.

[53] I wish to thank friends, colleagues, and this journal's two referees for their help. Special thanks to Ruth Manor who kept after me to make this article self-rewarding.

Prof. Michael F. Schmidt, Department of Philosophy, San Jose State University, One Washington Square, San Jose, California 95192-0096. 